\title{
Neighborhoods on the Rise: A Typology of Neighborhoods Experiencing Socioeconomic Ascent
}

\author{
Ann Owens* \\ Stanford University
}

Neighborhoods are an important source of inequality, and neighborhood change may lead to changing opportunities for residents. Past research on neighborhood upgrading tends to focus on one process: gentrification. I argue that a broader range of types of neighborhood socioeconomic ascent requires examination. This article documents the different types of neighborhoods ascending from 1970 to the present. Using principal components analysis and cluster analysis, I report the prevalence of socioeconomic ascent, based on increases in neighborhood income, rents, house values, and educational and occupational attainment, among five to seven types of neighborhoods in each decade. I also examine population and housing changes that co-occur with ascent to identify processes of ascent beyond gentrification. Overall, findings suggest mixed implications for neighborhood inequality. While white suburban neighborhoods make up the bulk of neighborhoods that ascend in each decade, minority and immigrant neighborhoods become increasingly likely to ascend over time, though displacement may occur.

Starting with the Chicago school, sociological theories of neighborhood change often focused on socioeconomic decline (Park and Burgess 1925). Following Wilson (1987), researchers documented the "social transformation" of inner-city neighborhoods into neighborhoods of concentrated poverty, resulting in a substantial body of urban scholarship on neighborhood decline (see Massey and Denton 1993; Jargowsky 1997). Beginning in the $1960 \mathrm{~s}$, scholars identified neighborhoods experiencing positive socioeconomic transformations, and a large body of literature on neighborhood gentrification followed (for overviews, see Zukin 1987; Lees, Slater, and Wyly 2008; Brown-Saracino 2010). Definitions of gentrification have varied in their emphasis on residents' demographic characteristics versus housing stock characteristics, rehabilitation versus rebuilding of housing, private versus public capital investments, cultural changes in neighborhoods, and consequences such as displacement (Lees, Slater, and Wyly 2008). While scholars acknowledge that gentrification can take diverse forms, the gentrification literature has coalesced around gentrification as a particular type of neighborhood ascent that includes the reinvestment of capital, displacement of existing residents, the entry of middle- or upper-class residents, and a change in the social, economic, cultural, and physical landscape of previously disinvested neighborhoods (Davidson and Lees 2005; Brown-Saracino $2010)$.

*Correspondence should be addressed to Ann Owens, Center for the Study of Poverty and Inequality, Stanford University, Building 370, 450 Serra Mall, Stanford, CA 94305; annowens@stanford.edu.

City E Community 11:4 December 2012

doi: $10.1111 /$ j.1540-6040.2012.01412.x

(C) 2012 American Sociological Association, 1430 K Street NW, Washington, DC 20005 
I argue that neighborhood socioeconomic ascent occurs in forms beyond gentrification that require investigation. I conceptualize ascent as neighborhoods that experience improving socioeconomic status (SES) regardless of socioeconomic origin, outcome, or process, with gentrification only one type of change falling under this umbrella. First, I develop a comprehensive measure of neighborhood ascent that identifies neighborhoods with relative increases in residents' average incomes, housing costs, and educational and occupational attainment compared to other neighborhoods in their metropolitan area from 1970 to 2009. Then I identify a typology of all neighborhoods in metropolitan areas in each decade since 1970 in terms of racial/ethnic and immigrant composition, population size, age of housing stock, residents' age distribution, family structure, and poverty rate, and estimate the likelihood of SES ascent over time for each neighborhood type. Finally, I identify a separate typology only among ascending neighborhoods and examine population changes that coincide with SES ascent. Where possible, I identify processes underlying these changes, though my aim is to emphasize the diversity of neighborhoods undergoing socioeconomic ascent and to set an agenda for further research.

Neighborhoods are one important social context that influences the life chances of individuals and are thus an important source of inequality (Logan 1978; Wilson 1987; Jencks and Mayer 1990). Therefore, understanding the full range of neighborhoods experiencing ascent is important because upwardly mobile neighborhoods change their position in the place stratification system, that is, the advantages associated with living in particular neighborhoods over others (Logan 1978). Upwardly mobile neighborhoods can either be sources of new residential opportunities or they can result in displacement. Overall, my findings suggest mixed implications for neighborhood inequality: while white suburban neighborhoods make up the bulk of neighborhoods that ascend in each decade, minority and immigrant neighborhoods have become increasingly likely to ascend over time. However, minority and lower-SES residents may be displaced as neighborhood ascent occurs, so the advantages of higher-SES neighborhoods may accrue to new residents.

\section{GENTRIFICATION AND OTHER FORMS OF NEIGHBORHOOD ASCENT}

In 1964, Ruth Glass coined the term gentrification to describe neighborhood change occurring in London: "many of the working class quarters of London have been invaded by the middle classes... until all or most of the original working class occupiers are displaced and the social character of the district is changed" (1964:xvii-xix). In subsequent research, debates have occurred around the causes of gentrification. Most prominently, demand-side explanations emphasize an emerging taste for urban living among the middle class, often spurred by the movement of artistic types (Glass 1964; Zukin 1982; Ley 1996), while production-side explanations emphasize investment opportunities in neighborhoods that have experienced disinvestment (Smith 1979, 1986). Gentrification scholars have also acknowledged the role of government intervention and private capital in spurring gentrification (Hackworth and Smith 2001; Lees, Slater, and Wyly 2008; BrownSaracino 2010).

The prototypical gentrifier is a well-educated, private-sector employee in a professional job, single or without a stay-at-home partner, with few or no children, and with 
substantial discretionary income (Zukin 1987; Ley 1996; Lees, Slater, and Wyly 2008). However, scholars also emphasize the role of artists, single and working women, homosexuals, families with children, and working and retired empty-nesters (Rose 1984; Zukin 1982, 1987; Cole 1987; Ley 1996). Gentrifiers are often portrayed as white, but higherSES blacks played a role in places like Harlem in New York City and North KenwoodOakland in Chicago (Taylor 2002; Freeman 2006; Pattillo 2007; McKinnish, Walsh, and White 2008). While scholars have debated various aspects of gentrification, the gentrification literature is focused on a particular type of urban ascent that involves reinvestment in neglected neighborhoods, changes in the physical and cultural landscape, and the production of revitalized neighborhoods with amenities appealing to upper-class clientele (Lees, Slater, and Wyly 2008; Brown-Saracino 2010).

Several researchers have identified the need to develop a broader framework for thinking about neighborhoods experiencing upward socioeconomic transitions. Van Criekingen and Decroly (2003) delineate four types of neighborhood renewal along five dimensions: neighborhoods' initial conditions, improvements to the built environment, social status growth, population change, and what type of neighborhood results from renewal. First, gentrification is the transformation of "deprived, low-income, inner-city neighborhoods into new wealthy areas based on population change (influx of affluent newcomers and displacement of initial inhabitants) and on improvements to the built environment” (2003: 2454). Second, marginal gentrification (see also Rose 1984) refers to neighborhood renewal by middle-class households who may be highly educated but not very wealthy. Van Criekingen and Decroly argue that marginal gentrification is not an early stage in the gentrification process but rather a separate process resulting in nonwealthy, but revitalized, neighborhoods. Third, neighborhood upgrading can occur in "slightly decayed and long-established bourgeois" neighborhoods in which younger families replace elderly households (2003: 2456). Finally, incumbent upgrading refers to neighborhood renewal in which moderate-income households improve their own housing conditions and the character of their neighborhood, so little population change occurs.

While this offers a broader framework than gentrification for understanding neighborhood ascent, there are still many other types of neighborhood ascent that can occur. For example, incumbent upgrading may not lead to changes in housing conditions; workingclass residents may replace very poor residents, so a wealthy neighborhood is not the result; or changes to the built environment may or may not co-occur with neighborhood ascent. Both city and suburban neighborhoods can experience ascent. In addition, neighborhood ascent can occur through public or private investment rather than just population changes. This article moves beyond the focus on gentrification to document all types of neighborhoods undergoing ascent.

\section{NEIGHBORHOOD CHANGE AND NEIGHBORHOOD ASCENT}

Sociological models of neighborhood change suggest alternative processes of ascent. The classic invasion-succession model of urban change describes how residents sort themselves by SES, and neighborhoods decline as lower-SES residents "invade and succeed" higher-SES neighborhoods (Park and Burgess 1925). While this model is generally used to explain neighborhood decline, residential change can result in ascending districts if higher-SES "invaders" cluster together, pricing out lower-SES residents and creating 
higher-SES areas (McKenzie 1925). Underlying this theory of neighborhood change are individuals' residential decisions, which lead to emergent change at the neighborhood level (Schelling 1971; Bruch and Mare 2006). Sampson and Sharkey (2008) provide evidence that individual-level mobility can lead to stability as well as change. They find that many individuals move to the same racial-economic neighborhood subtype as their origin neighborhood. This suggests that there is an enduring structure of neighborhood inequality, and neighborhood ascent might more commonly result from moderate changes as slightly higher-SES residents move to neighborhoods where individuals similar to them already live rather than drastic population change as depicted by gentrification.

Other models of neighborhood change consider cities' and neighborhoods' political, economic, and social structures. The neighborhood life-cycle model suggests that public redevelopment and regulation may account for neighborhoods' movement through the stage of renewal (Schwirian 1983). Logan and Molotch (1987) provide a political economy model of urban change in which neighborhoods compete for locational advantages. Government interventions and private investments are one way that neighborhoods can experience SES ascent (Molotch 1976; Logan 1978). Federal place-based policies like Community Development Block Grants and Employment Zones, subsidized housing policies like HOPE VI and the Low Income Housing Tax Credit program, and local initiatives like community development corporations and zoning laws have led to ascent since the 1970s (Hyra 2008; Rothwell and Massey 2008; Goetz 2010). Often, these initiatives focus on preventing displacement of residents, and improvements to neighborhood SES are often quite modest. Therefore, government and/or private interventions can lead to ascent that may not be considered gentrification.

Sociological research describes several cases of neighborhood ascent that may fall outside the gentrification framework. First, black middle-class neighborhoods were created as educated and married blacks and those who were homeowners moved out of poor inner-city neighborhoods into higher-SES areas in the 1970s and 1980s (Wilson 1987; Massey and Eggers 1990; Quillian 1999). Later research showed that black middle-class residents worked to keep lower-class residents out, indirectly displacing them, to maintain higher-SES neighborhoods (Wilson and Taub 2006; Pattillo 2007). Black middle-class neighborhoods span the SES spectrum from neighborhoods with poverty rates around 20 percent to more affluent black suburbs (Pattillo 2005; Lacy 2007). Therefore, as black middle-class neighborhoods are created, they may represent several types of neighborhood ascent that would not all be captured by gentrification if, for example, they do not result in upper-class neighborhoods, do not lead to changes in the built environment, or are outside disinvested urban areas. I anticipate that low-SES minority neighborhoods, particularly black neighborhoods, will make up only a small proportion of ascending neighborhoods given whites' strong racial preferences against living with blacks (Charles 2003) and growing black class segregation (Massey and Fischer 2003). Therefore, minority residents and their neighborhoods may not benefit from ascent.

Second, SES ascent occurred among poor "underclass" neighborhoods that experienced improvements in SES during the 1990s. The number of neighborhoods with poverty rates over 40 percent declined during the $1990 \mathrm{~s}$, as nearly $1 / 3$ of them experienced poverty rate declines of 5 points or more (Jargowsky 2003; Galster et al. 2003). Ellen and O'Regan (2008) find that half of very poor neighborhoods experienced increases in relative neighborhood income, and McKinnish, Walsh, and White (2008) find that mean family income increased by $\$ 10,000$ or more in 15 percent of low income 
Census tracts during the 1990s. These neighborhoods could be examples of "marginal gentrification," since they do not become wealthy neighborhoods, but it could be that working class or lower-middle-class residents, rather than highly educated but moderate income residents, are moving in, and improvements to the built environment may not occur.

Past work focuses on the renewal of existing neighborhoods, but neighborhood ascent can also occur through suburbanization. In the early- and mid-twentieth century (and through the present, with sprawl and the development of exurban areas [Squires 2002]), suburbs provided a new place for residents to live, and these early suburbs were typically white and high SES (Jackson 1985; Baldassare 1992). New suburban communities experienced SES ascent as they went from having no population to having some residents. These neighborhoods then became a new residential option in the distribution of neighborhoods in metropolitan areas chosen by an increasing proportion of Americans over time-from 37 percent in 1970 to 50 percent in 2000 (Baldassare 1992; Hobbs and Stoops 2002). After their creation, suburbs vary in their SES trajectories, with some inner-ring suburbs particularly vulnerable to decline (Hanlon 2009, 2011) while others experience "suburban gentrification" (Lees, Slater, and Wyly 2008). Rather than defining suburban ascent as gentrification, scholars should develop a new, more specific way to describe it, as urban gentrification emphasizes a return to the city by those seeking authenticity that cannot be found in the suburbs (Ley 1996). Economic segregation has increased at a macrogeographic scale, suggesting the concentration of affluent residents in suburban enclaves (Reardon and Bischoff 2011). Therefore, I hypothesize that suburban areas will comprise a large proportion of ascending neighborhoods, suggesting that neighborhood inequality will be maintained or exacerbated as already high-SES neighborhoods experience SES improvements.

\section{A TYPOLOGY OF ASCENT}

Research on neighborhood ascent has begun to move beyond gentrification, but the full range of neighborhood types experiencing ascent, its overall prevalence, and neighborhoods' changing likelihood to experience ascent over time is undocumented. One paper that provides a more comprehensive picture of neighborhood change is Morenoff and Tienda (1997), who use cluster analysis to develop a typology of urban neighborhood change by social class among Chicago neighborhoods, looking at transitions among these types over time. Their typology identifies "gentrifying yuppie neighborhoods," and they argue that white neighborhoods tend to follow this path while black neighborhoods are more likely to ascend from working to middle-class neighborhoods.

Extending their work, I document SES ascent of all types in urban and suburban neighborhoods from 1970 to 2009. Morenoff and Tienda define neighborhood clusters based on social class, excluding race, and focus on transitions among neighborhood SES categories, examining if black or white neighborhoods make certain types of transitions. I include racial composition in my neighborhood typology, as I anticipate it will be key in differentiating neighborhoods given residential segregation (Massey and Denton 1993), and then identify each type's likelihood to ascend in each decade since 1970. I then identify a separate typology of only neighborhoods that experienced ascent to see if unique neighborhood types emerge and to assess the degree of population change accompanying neighborhood SES ascent. 
Identifying a typology can serve as an important mechanism for theory development. By documenting the full range of neighborhoods experiencing SES ascent, I identify cases that do not fit the gentrification framework, demonstrating that a broader and more comprehensive theory of neighborhood ascent is required. Further, examining the full range of SES ascent allows for a better understanding of the implications of neighborhood SES improvement for neighborhood inequality. Gentrification emphasizes the displacement of low-SES residents, but ascent can also alleviate or deepen neighborhood inequality if it affects some types of neighborhoods, in terms of racial/ethnic composition, urbanity, and economic profile, more than others over time.

\section{DATA AND ANALYSES}

Decennial Census data on neighborhoods' socioeconomic, population, and housing characteristics come from the Neighborhood Change Database (NCDB), produced by Geolytics, from 1970 to 2000, and similar data from 2005 to 2009 come from the American Community Survey (ACS). I define neighborhoods as Census tracts, following most quantitative research on neighborhoods. The NCDB provides estimates of Census tract characteristics with all tract boundaries normalized to 2000 boundaries, allowing for easy comparison of the same areas over time. This means the data include some tracts that had no population in years prior to 2000. I use only tracts that are in Metropolitan Statistical Areas (MSAs) as defined in 1999 ( $N=51,448$ tracts). ${ }^{1}$ Using 1999 MSA definitions means that some tracts defined as being in a metropolitan area were not considered as such prior to 1999 . For my analyses, tracts with no population before 2000 or that were initially not considered part of a metropolitan area are meaningful data points. I include in my definition of neighborhood ascent those neighborhoods that essentially did not exist in one decade but emerged in another through suburbanization, sprawl, or conversion of an industrial area to a residential area because these neighborhoods provide new opportunities for residence. (I describe results omitting these neighborhoods in the Supplemental Material.)

The ACS 5-year estimates aggregate annual surveys from 2005 to 2009, resulting in several comparability issues with Census data. First, the aggregate nature of the data masks changing characteristics of neighborhoods-if neighborhoods change rapidly, they will look different in 2005 than in 2009, but these data represent a composite picture of an area over 60 months. Second, the annual sampling frame for the ACS is about 1 in 15 households, compared to about 1 in 6 for the decennial Census, so sampling errors are larger. Third, the ACS sampling frame is based on the 2000 Census population data, so tracts that grew rapidly will be under-represented. I use these data because they are the only national-level data on tract-level economic characteristics available after 2000, and the key variables I examine are comparable from 2000 to 2005-2009 (U.S. Census Bureau, 2009).

\section{MEASURING NEIGHBORHOOD ASCENT}

I define neighborhood ascent as neighborhoods in which, at the aggregate level, residents' income, housing costs, and educational and occupational attainment increased. Including housing costs ensures that ascent captures real changes to neighborhoods as 
TABLE 1. Neighborhood SES Indicators for Ascending Neighborhoods by Decade, 1970 to 2005-2009

\begin{tabular}{|c|c|c|c|c|c|c|c|c|}
\hline & \multicolumn{8}{|c|}{ Ascending Neighborhoods } \\
\hline & \multicolumn{2}{|c|}{1970 to 1980 Ascent } & \multicolumn{2}{|c|}{1980 to 1990 Ascent } & \multicolumn{2}{|c|}{1990 to 2000 Ascent } & \multicolumn{2}{|c|}{2000 to $2005-2009$ Ascent } \\
\hline & 1970 & 1980 & 1980 & 1990 & 1990 & 2000 & 2000 & 2005-2009 \\
\hline Avg $\mathrm{HH}$ income & $\$ 36,725$ & $\$ 61,716$ & $\$ 40,676$ & $\$ 71,114$ & $\$ 55,637$ & $\$ 76,873$ & $\$ 61,726$ & $\$ 68,635$ \\
\hline Avg rent & $\$ 30$ & $\$ 832$ & $\$ 635$ & $\$ 907$ & $\$ 737$ & $\$ 920$ & $\$ 774$ & $\$ 988$ \\
\hline Avg house value & $\$ 65,210$ & $\$ 196,102$ & $\$ 183,866$ & $\$ 212,595$ & $\$ 154,658$ & $\$ 220,410$ & $\$ 168,892$ & $\$ 274,740$ \\
\hline$\%$ with BA & 6.10 & 19.34 & 13.10 & 23.10 & 15.22 & 26.18 & 18.28 & 27.74 \\
\hline $\begin{array}{l}\% \text { with high-status } \\
\text { job }\end{array}$ & 14.50 & 28.72 & 20.87 & 33.01 & 24.09 & 35.54 & 26.85 & 36.99 \\
\hline $\begin{array}{l}\mathrm{N} \text { of ascending } \\
\text { tracts }\end{array}$ & \multicolumn{2}{|c|}{10,587} & \multicolumn{2}{|c|}{8,399} & \multicolumn{2}{|c|}{6,969} & \multicolumn{2}{|r|}{7,039} \\
\hline $\begin{array}{c}\% \text { of tracts that } \\
\text { ascended }\end{array}$ & \multicolumn{2}{|c|}{$20.58 \%$} & \multicolumn{2}{|c|}{$16.33 \%$} & \multicolumn{2}{|c|}{$13.55 \%$} & \multicolumn{2}{|c|}{$13.68 \%$} \\
\hline
\end{tabular}

places as well as changes to residents' SES. To examine ascent beyond gentrification, I do not only examine initially low SES or disinvested neighborhoods, nor do I require that population turnover occur or that wealthy neighborhoods be the end product. Changes in the type of housing stock, business and cultural amenities, and infrastructure may also occur, but I focus on residents' SES and housing costs.

To measure neighborhood ascent, I draw on past research that used discriminant analysis to identify characteristics distinguishing gentrified areas from other types of areas (Schuler, Kent, and Monroe 1992; Hammel and Wyly 1996; Wyly and Hammel 1998, 1999; Heidkamp and Lucas 2006). Discriminant analysis evaluates observations classified a priori into categories and identifies variables that best distinguish between the categories. Based on my review of this literature and my conception of neighborhood ascent, I chose five variables that have been shown to distinguish between ascending and nonascending tracts: household income, educational attainment, occupation type, rent, and house values. While these indicators have been used in gentrification research, they neither distinguish between population turnover and incumbent upgrading, nor do they limit analyses to a certain initial or final economic status. Therefore, these indicators apply to all types of ascending neighborhoods, not just gentrification. Specifically, I examine Census tracts' average household income, average house values, average gross rent, proportion of residents over 25 years old with a BA, and proportion of workers over 16 years old working in a managerial, technical, or professional (high-status) job. ${ }^{2}$ Tracts with no residents, no rental housing, or no owner-occupied homes were assigned a value of 0 for the relevant indicators and retained in analyses.

I calculate a neighborhood SES score based on these five variables using principal components analysis (PCA) separately in 1970, 1980, 1990, 2000, and 2005-2009. PCA is a way to combine many correlated variables into one indicator by assessing the similarities and differences among the variance of each variable. PCA reveals if there is one or more underlying "dimensions" that summarize the many original variables. In each year, PCA showed that only one underlying factor captured neighborhood SES (i.e., only one factor had an eigenvalue over 1; see Table A1 for factor loadings from PCA). In each year, I estimate one neighborhood SES factor score that reflects the relative strength of each of the variables according to PCA results. 
To measure ascent, I identify which neighborhoods experienced SES improvements relative to other neighborhoods in their metropolitan area during each decade. In each year, I assign every neighborhood a score of 1 to 100 based on the percentile distribution of neighborhood SES factor scores within that neighborhood's MSA. Then, I define ascent as a neighborhood whose neighborhood SES percentile score within its metropolitan area increased over each decade. To capture substantial and meaningful changes in neighborhood SES, I impose the condition that the percentile score must increase by 10 percentile points. ${ }^{3}$ My measurement of ascent is more comprehensive than only considering income or poverty rates, commonly used in past research assessing neighborhood improvement.

I measure ascent relative to the tracts in a neighborhood's MSA for several reasons. First, both absolute levels and variation in neighborhood SES varies across MSAs, so identifying an absolute threshold of ascent would be very difficult. A neighborhood in an MSA with a comparatively narrow distribution of neighborhood SES could experience SES improvement that would not substantially change its position in national rankings even if it went from the bottom to the top of neighborhoods within its MSA. Second, measuring within-MSA stratification is consistent with my focus on neighborhood inequality: families typically look within particular MSAs rather than across the whole nation when considering residential opportunities available to them. Finally, looking within MSAs effectively controls for MSA-level differences in economic conditions and changes so MSA-wide improvements are not conflated with neighborhood improvements.

Table 1 presents the mean of each neighborhood SES indicator for ascending tracts at the beginning and end of the decade in which they ascended (e.g., the first column shows the 1970 and 1980 characteristics of tracts that ascended during the 1970s). All dollar amounts are reported in 2009 dollars, adjusted for inflation using the Consumer Price Index Research Series. The rent value is extremely low in 1970, and rent in 1970 actually has a negative factor loading (see Table A1) because 38 percent of ascending tracts from 1970 to 1980 had no rental housing and thus average rents of $\$ 0$ in $1970 .^{4}$

The bottom row of Table 1 shows the proportion of all metropolitan tracts that experienced SES ascent during each decade. I assess ascent separately in each decadefrom 1970 to 1980,1980 to 1990,1990 to 2000 , and 2000 to $2005-2009 .^{5}$ As Table 1 shows, the highest proportion (20.6 percent) of tracts ascended from 1970 to 1980 , while the lowest proportion (13.6 percent) ascended from 1990 to 2000. This contrasts with work documenting neighborhood improvement during the economic boom of the 1990s. Ellen and O'Regan (2008) find that 29 percent of central-city tracts experienced increases in relative income ratios during the 1970s and 1980s while 41 percent of neighborhoods experienced an increase during the 1990s. One explanation for these different findings, which becomes clear as I describe types of neighborhoods likely to ascend, is that I include tracts that had no population prior to 2000, particularly in 1970, and these tracts experience SES ascent during the 1970s and 1980s because they had initial values of zero on all SES indicators. ${ }^{6}$ My results also differ from Ellen and O'Regan because I use a composite SES measure while they use income; they also sample central-city tracts while I use all tracts in metropolitan areas. London and Palen (1984) identified only about 100 neighborhoods in America's largest 30 cities as undergoing gentrification during the 1970s, illustrating that ascent covers a much broader phenomenon. 


\section{POPULATION AND HOUSING VARIABLES}

After identifying ascending neighborhoods, I turn to describing their characteristics. I include a set of traits capturing characteristics of both residents and the built environment: racial/ethnic and immigrant composition, population, number of households, proportion of housing built in the last decade, age distribution, family structure, poverty rate, and location in the city or not. For race/ethnicity, from 1980 onward, I describe the proportions of non-Hispanic whites, non-Hispanic blacks, non-Hispanic Asians, and Hispanics. From 1970 to 1980, I compare all whites, blacks, and Hispanics because 1970 NCDB data do not split races by Hispanic ethnicity or provide a count of Asian residents. (In 1980, the proportion of residents who are non-Hispanic Asian includes those of American Indian, Asian, Native Hawaiian, other Pacific Island, and other origin descent. From 1990 onward, the measure is proportion non-Hispanic Asian, Native Hawaiian, and other Pacific Island.) To capture the age distribution, I include the proportion of young children (under 5 years old), all children (under 18 years old), and elderly residents (over 65 years old). I also report the proportion of female-headed households with children. I use the 1999 definitions of Census places considered the city or cities within an MSA to identify city tracts, describing all other tracts as suburban. ${ }^{7}$ In the next section, I create a typology of neighborhoods based on these variables and note which types are most likely to experience SES ascent.

\section{WHAT TYPES OF NEIGHBORHOODS ARE MOST LIKELY TO ASCEND?}

Following Hanlon (2009), I use PCA and cluster analysis to identify a typology of neighborhoods among all Census tracts in metropolitan areas. I conduct PCA on the 14 population and housing variables described in the previous section-proportion white, black, Asian, Hispanic, and foreign-born; population size; number of households; proportion of housing built in the last decade; proportion of children under 5 , children under 18 , and people over 65; proportion of households headed by a single female with children; poverty rate; and if the tract was in a city-as well as the five SES variables-mean income, mean house value, mean rent, proportion of residents with a BA, and proportion of residents with a high-status job. I perform PCA separately for each year, retaining factors with an eigenvalue of 1 or greater. The variables were summarized into five factors, or dimensions, in 1970, 1980, 1990, and 2000 and six factors in 2005-2009. ${ }^{8}$ I estimated factor scores in each year for every tract.

Then I cluster these factor scores using k-means clustering to classify neighborhoods into a typology of neighborhoods in each year. This clustering approach uses an iterative process to group observations according to similarities in the factor scores' mean values (note that the use of "cluster" does not denote spatial clustering but rather grouping based on similarity of neighborhood characteristics). It allows the analyst to specify the number of clusters, and I use the number of factors retained in the PCA to determine how many neighborhood types to specify. ${ }^{9}$ While cluster analysis groups similar neighborhoods together, there is still some diversity within each type. However, cluster analysis is an established and appropriate approach to identifying the most substantial distinctions among a large number of diverse neighborhoods (Morenoff and Tienda 1997; Sucoff 
TABLE 2. Average of 1970 to 2005-2009 Characteristics for All Metropolitan Tracts and by Neighborhood Type

\begin{tabular}{|c|c|c|c|c|c|c|c|c|c|}
\hline & $\mathrm{All}^{\S}$ & $\begin{array}{l}\text { Minority } \\
\text { Urban }\end{array}$ & Affluent & $\begin{array}{l}\text { Diverse } \\
\text { Urban }\end{array}$ & $\begin{array}{c}\text { No } \\
\text { Population }\end{array}$ & $\begin{array}{c}\text { New } \\
\text { White } \\
\text { Suburbs }\end{array}$ & $\begin{array}{c}\text { Upper- } \\
\text { Middle- } \\
\text { Class } \\
\text { White } \\
\text { Suburbs }\end{array}$ & $\begin{array}{c}\text { Booming } \\
\text { Suburbs }\end{array}$ & $\begin{array}{l}\text { Hispanic } \\
\text { Enclaves }\end{array}$ \\
\hline$\%$ White* & $75.62 \%$ & $23.28 \%$ & $83.98 \%$ & $52.48 \%$ & $9.61 \%$ & $90.20 \%$ & $84.24 \%$ & $75.08 \%$ & $23.52 \%$ \\
\hline$\%$ Black & $13.16 \%$ & $63.25 \%$ & $4.48 \%$ & $9.00 \%$ & $2.31 \%$ & $4.34 \%$ & $6.24 \%$ & $8.32 \%$ & $14.01 \%$ \\
\hline$\%$ Asian & $3.76 \%$ & $2.12 \%$ & $6.83 \%$ & $15.42 \%$ & $0.52 \%$ & $1.64 \%$ & $1.94 \%$ & $3.93 \%$ & $4.21 \%$ \\
\hline$\%$ Hispanic & $10.20 \%$ & $11.61 \%$ & $5.85 \%$ & $29.15 \%$ & $0.64 \%$ & $4.26 \%$ & $5.74 \%$ & $10.37 \%$ & $57.41 \%$ \\
\hline \% Foreign born & $9.32 \%$ & $8.35 \%$ & $11.72 \%$ & $25.11 \%$ & $0.77 \%$ & $3.73 \%$ & $5.56 \%$ & $9.52 \%$ & $33.33 \%$ \\
\hline Tract population & 3841.12 & 3590.23 & 4239.82 & 3664.61 & 108.75 & 2498.29 & 4568.00 & 8861.49 & 5036.42 \\
\hline $\mathrm{N}$ of households & 1362.11 & 1116.46 & 1472.52 & 1179.31 & 129.28 & 818.51 & 1560.03 & 2779.32 & 1103.93 \\
\hline$\%$ New housing ${ }^{\dagger}$ & $20.18 \%$ & & $15.26 \%$ & $12.13 \%$ & $1.53 \%$ & $41.06 \%$ & $17.04 \%$ & $28.24 \%$ & $6.28 \%$ \\
\hline $\begin{array}{c}\% \text { Residents } \\
\text { under } 18\end{array}$ & $26.32 \%$ & $31.60 \%$ & $22.85 \%$ & $25.89 \%$ & $0.96 \%$ & $31.93 \%$ & $24.01 \%$ & $26.89 \%$ & $29.56 \%$ \\
\hline $\begin{array}{c}\% \text { Residents } \\
\text { under } 5\end{array}$ & $7.61 \%$ & $9.44 \%$ & $6.32 \%$ & $8.15 \%$ & $0.20 \%$ & $9.27 \%$ & $7.02 \%$ & $7.46 \%$ & $9.34 \%$ \\
\hline $\begin{array}{l}\% \text { Residents over } \\
65\end{array}$ & $11.14 \%$ & $10.40 \%$ & $13.56 \%$ & $12.80 \%$ & $2.23 \%$ & $8.05 \%$ & $13.08 \%$ & $10.16 \%$ & $8.70 \%$ \\
\hline $\begin{array}{c}\% \text { Fem-headed } \\
\text { households }\end{array}$ & $18.16 \%$ & $42.41 \%$ & $12.78 \%$ & $21.60 \%$ & $1.12 \%$ & $12.10 \%$ & $15.62 \%$ & $14.42 \%$ & $16.62 \%$ \\
\hline Poverty rate & & $30.39 \%$ & & & $2.20 \%$ & & & & $22.17 \%$ \\
\hline $\begin{array}{l}\% \text { Tracts in } \\
\text { central city }\end{array}$ & $42.66 \%$ & $84.38 \%$ & $44.84 \%$ & $66.03 \%$ & $26.32 \%$ & $24.81 \%$ & $24.22 \%$ & $19.12 \%$ & $57.87 \%$ \\
\hline Avg HH income & $\$ 64,156$ & $\$ 39,891$ & $\$ 96,461$ & $\$ 55,747$ & $\$ 7,572$ & $\$ 62,601$ & $\$ 68,461$ & $\$ 83,697$ & $\$ 53,078$ \\
\hline Avg house value & $\$ 187,716$ & $\$ 106,112$ & $\$ 322,465$ & $\$ 212,161$ & $\$ 7,114$ & $\$ 153,423$ & $\$ 181,112$ & $\$ 236,234$ & $\$ 282,130$ \\
\hline Avg rent & $\$ 709$ & $\$ 586$ & $\$ 981$ & $\$ 737$ & $\$ 42$ & $\$ 553$ & $\$ 834$ & $\$ 1,022$ & $\$ 974$ \\
\hline$\% \mathrm{BA}$ & $20.50 \%$ & $9.41 \%$ & $36.66 \%$ & $17.89 \%$ & $1.27 \%$ & $16.95 \%$ & $22.37 \%$ & $30.57 \%$ & $14.04 \%$ \\
\hline$\%$ High-status job & $28.83 \%$ & $17.84 \%$ & $42.53 \%$ & $24.90 \%$ & $2.30 \%$ & $27.62 \%$ & $31.39 \%$ & $37.66 \%$ & $19.98 \%$ \\
\hline
\end{tabular}

* In 1970, the race categories are not separated by ethnicity. After 1970, white, black, and Asian refer to non-Hispanic whites, non-Hispanic blacks, and non-Hispanic Asians. The racial composition variables do not sum to $100 \%$ because they are the averages of racial composition across all neighborhoods in the cluster, rather than the racial composition of all people in the cluster. Additionally, I do not include American Indian or other racial/ethnic groups.

${ }^{\dagger}$ Measured as the proportion of housing units built in the last 10 years.

${ }^{\ddagger}$ All dollar amounts have been adjusted to 2009 dollars using the Consumer Price Index Research Series.

$\S$ The $\mathrm{N}$ of total neighborhoods is 51,448 . The $\mathrm{N}$ in each type varies from 1970 to $2005-09$. Some types do not exist in all years, and averages reflect only the years in which they exist. Table 4 presents the proportion of all 51,448 tracts that were in each category in each year, so one can estimate the $\mathrm{N}$ of neighborhoods in each category in each year from Table 4.

and Upchurch 1998; Hanlon 2009, 2011; Wyly and DeFilippis 2010). Individual tracts can be considered different neighborhood types over time, either reflecting real changes in their characteristics or closer similarity to different types over time. ${ }^{10}$

Table 2 presents the mean of each variable for all Census tracts in MSAs as well as by neighborhood type averaged over all years. I label each neighborhood type based on the traits that most predominantly differentiate it from other neighborhood types. Table 3 summarizes the key characteristics of each type that define its character. Table 3 also includes likely ascent processes, which I discuss later.

The top half of Table 4 presents the frequency distribution of the typology among all metropolitan tracts from 1970 to 2005-2009. The bottom half of Table 4 presents the proportion of tracts in each neighborhood type that experienced SES ascent (a 10-point increase on the percentile distribution of neighborhood SES factor scores within the neighborhood's MSA) in the decade following their initial type classification. While PCA and cluster analyses were done separately in each year, three neighborhood 
TABLE 3. Typology of All Metropolitan Tracts

\begin{tabular}{|c|c|c|}
\hline Type & Key Distinguishing Characteristics & Likely Processes of Ascent \\
\hline Minority urban neighborhoods & $\begin{array}{l}\text { - Majority minority } \\
\text { - Central-city } \\
\text { - Highest poverty rates, lowest SES } \\
\text { - High\% of households headed by } \\
\text { female }\end{array}$ & $\begin{array}{l}\text { - Middle-class in-migration } \\
\text { - Government intervention } \\
\text { - Incumbent upgrading }\end{array}$ \\
\hline Affluent neighborhoods & $\begin{array}{l}\text { - White residents; foreign-born residents } \\
\text { - } 45 \% \text { in central city } \\
\text { - Highest SES }\end{array}$ & $\begin{array}{l}\text { - Invasion-Succession } \\
\text { - Exclusionary processes } \\
\text { - Incumbent upgrading } \\
\text { - Gentrification }\end{array}$ \\
\hline Diverse urban neighborhoods & $\begin{array}{l}\text { - Racially mixed cluster (and most } \\
\text { racially mixed tracts) } \\
\text { - } 2 / 3 \text { in central city } \\
\text { - City-average poverty rate }\end{array}$ & $\begin{array}{l}\text { - Marginal gentrification } \\
\text { - Invasion-Succession } \\
\text { - Incumbent upgrading }\end{array}$ \\
\hline No population & $\begin{array}{l}\text { - Zero/low population } \\
\text { - } \frac{3}{4} \text { in suburbs }\end{array}$ & $\begin{array}{l}\text { - Suburbanization/sprawl } \\
\text { - Conversion to residential }\end{array}$ \\
\hline New white suburbs & $\begin{array}{l}\text { - } 90 \% \text { White } \\
\text { - Smaller population } \\
\text { - High } \% \text { of new housing } \\
\text { - } \frac{3}{4} \text { in suburbs }\end{array}$ & - Suburbanization/sprawl \\
\hline Upper-middle-class white suburbs & $\begin{array}{l}\text { - } 85 \% \text { white } \\
\text { - } \frac{3}{4} \text { in suburbs } \\
\text { - High SES }\end{array}$ & $\begin{array}{l}\text { - Suburbanization } \\
\text { - Incumbent upgrading } \\
\text { - Exclusionary processes }\end{array}$ \\
\hline Booming suburbs & $\begin{array}{l}\text { - Twice as large as typical tract } \\
\text { - } 80 \% \text { in suburbs } \\
\text { - Slightly less white, more foreign born } \\
\text { than other suburbs } \\
\text { - High SES }\end{array}$ & $\begin{array}{l}\text { - Middle-class in-migration } \\
\text { - Incumbent upgrading }\end{array}$ \\
\hline Hispanic enclave neighborhoods & $\begin{array}{l}\text { - Majority Hispanic } \\
\text { - } 1 / 3 \text { foreign-born } \\
\text { - Moderately high poverty rate } \\
\text { - } 60 \% \text { in central city }\end{array}$ & $\begin{array}{l}\text { - Creation of immigrant ethnic } \\
\text { communities } \\
\text { - Incumbent upgrading }\end{array}$ \\
\hline
\end{tabular}

types existed in all years (though the particular neighborhoods in these categories may change over time): minority urban neighborhoods, affluent neighborhoods, and diverse urban neighborhoods.

The minority urban neighborhood type, which is most common in the South, likely captures both black underclass neighborhoods with very high poverty rates and neighborhoods where black middle-class residents live. As Pattillo (2005) shows, the average black middle-class resident in Philadelphia lived in a much lower-SES neighborhood (average poverty rate of 20.4 percent) than the average white middle-class resident (average neighborhood poverty rate of 7.4 percent). Therefore, although black class segregation has increased (Massey and Fischer 2003), black underclass neighborhoods and those where middle-class residents live may not be distinct using cluster analysis-race more dominantly delineates minority neighborhoods than class. In all years but 2000 , minority urban neighborhoods were over 60 percent black, but in 2000, these neighborhoods were about 40 percent black and 30 percent Hispanic. In 2000, the prevalence of these neighborhoods is highest (nearly 25 percent) because the category combines black and Hispanic neighborhoods, while Hispanic neighborhoods are included in other categories in 
TABLE 4. Neighborhood Types among All Metropolitan Tracts and the Proportion of each Type Experiencing SES Ascent, 1970 to 2005-2009

\begin{tabular}{|c|c|c|c|c|c|}
\hline & \multicolumn{5}{|c|}{ Proportion of all Tracts $(\mathrm{N}=51,448)$} \\
\hline & 1970 & 1980 & 1990 & 2000 & 2005-2009 \\
\hline Minority urban neighborhoods & 7.42 & 10.81 & 11.82 & 23.44 & 13.60 \\
\hline Affluent neighborhoods & 28.75 & 40.05 & 16.43 & 13.21 & 21.44 \\
\hline Diverse urban neighborhoods & 10.47 & 7.94 & 9.77 & 21.19 & 4.35 \\
\hline No population & 11.52 & 3.87 & & & \\
\hline New white suburbs & 41.84 & 37.33 & 35.78 & & \\
\hline Upper-middle-class white suburbs & & & 26.21 & 27.84 & 35.67 \\
\hline Booming suburbs & & & & 14.27 & 10.46 \\
\hline Hispanic enclaves & & & & & 14.48 \\
\hline \multirow[t]{3}{*}{ Total $(\mathrm{N}=51,448$ tracts $)$} & $100 \%$ & $100 \%$ & $100 \%$ & $100 \%$ & $100 \%$ \\
\hline & \multicolumn{5}{|c|}{ Proportion of Each Type that Experienced Ascent } \\
\hline & $1970-1980$ & 1980-1990 & 199 & & 2000-2009 \\
\hline Minority urban neighborhoods & 19.21 & 10.70 & & & 16.57 \\
\hline Affluent neighborhoods & 8.74 & 11.30 & & & 5.31 \\
\hline Diverse urban neighborhoods & 17.19 & 15.41 & & & 16.22 \\
\hline No population & 46.47 & 48.12 & & & \\
\hline New white suburbs & 22.68 & 20.28 & & & \\
\hline Upper-middle-class white suburbs & & & & & 16.25 \\
\hline Booming suburbs & & & & & 7.83 \\
\hline
\end{tabular}

Notes: Proportions in the lower panel do not add up to $100 \%$ either across rows or columns because they represent the proportion of neighborhoods in each type that experienced ascent. For example, in 1970, 7.42\% of all 51,448 neighborhoods, or $\sim 3,817$ neighborhoods, were minority urban neighborhoods (see upper panel), and $19.21 \%$ of these neighborhoods ascended from 1970 to 1980.

other decades. Looking at the bottom half of Table 4, about 20 percent of minority urban neighborhoods ascended during the 1970s. The proportion of minority urban neighborhoods experiencing SES ascent fell to about 10 percent in the 1980s and 1990s but has increased to 17 percent since 2000.

The second neighborhood type identified in all years is affluent neighborhoods. The prevalence of these neighborhoods declines over time, as Table 4 shows, from 30-40 percent in 1970 and 1980 to 10-20 percent after these years. I use the label affluent neighborhoods following Lee and Marlay (2007), who find a similar demographic profile of white and foreign-born residents in affluent neighborhoods. However, their definition of affluence is much more exclusive, as only the top 2 percent of neighborhoods are defined as such. The prevalence of these neighborhoods in my typology is highest in 1980, when the SES profile was slightly less exclusive. From 1990 to 2005-2009, the average household income in this type is over $\$ 100,000$ and half the residents have BA degrees and high-status jobs. Affluent neighborhoods have among the lowest rates of neighborhood SES ascent, about 5 percent after 1990, perhaps because they already have such high SES that they cannot substantially improve their standing in their MSA's neighborhood SES distribution (though they may still become more affluent in absolute terms).

I call the third neighborhood type present in all years diverse urban neighborhoods because many different types of working- or middle-class city neighborhoods are 
represented. On average, the neighborhoods are a mix of all races, primarily white and Hispanic from 1970 to 1990, a fairly representative mix of the U.S. population in 2000, and white, Asian, and Hispanic residents in 2005-2009. Of course, the cluster averages are for all tracts in the cluster, so it could be that racially or ethnically homogenous neighborhoods from several racial/ethnic groups fall into this type. However, this type has the most neighborhoods in which no racial/ethnic group makes up 50 percent or more of the population in each decade. About 15 percent of diverse urban neighborhoods experience SES ascent in each decade.

While these three neighborhood types occur in all years, other types blend together or emerge as distinct categories over time. In 1970 and 1980, a neighborhood type that I call no population existed, most common in the South and West. ${ }^{11}$ Only 20-30 percent of these tracts are located in the city, as defined in 1999, suggesting they are primarily suburban or exurban. In 1970, 98 percent of neighborhoods in this group had a tract population of zero, and in 1980, 78 percent of these tracts had zero residents. These tracts comprised about 10 percent of all neighborhoods in 1970 and fewer than 5 percent in 1980. By 1990, these tracts are no longer prominent enough to comprise a type of neighborhood in MSAs. These tracts had the highest rates of ascent in the 1970s and 1980s because, without any residents, they are at the bottom of the neighborhood SES distribution and can only improve.

Three types of suburbs exist over time, representing a "life cycle" of suburbs. A neighborhood type that I call new white suburbs existed from 1970 to 1990 . They have the highest proportion of new housing built in the last decade (50 percent in 1970 and 1980, 25 percent in 1990) and they have a small tract population compared to the average of 4,000-since tract delineations are based on 2000 characteristics, this suggests that these neighborhoods were just becoming populated prior to 2000. About 20 percent of new white suburbs experienced SES ascent, and these neighborhoods were the most likely to ascend in the 1990s and the second most common, after no population tracts, in the 1970 s and 1980s.

In 1990, 2000, and 2005-2009, upper-middle-class white suburbs emerged as a distinct neighborhood type. In 1990, these neighborhoods differ from the new white suburb type in that they are larger and have a lower proportion of new housing, suggesting they have existed longer. Upper-middle-class white suburbs comprise 25-35 percent of all neighborhoods in each decade, becoming increasingly common over time, and 10 percent experience SES ascent during the 1990s while 16 percent experience SES ascent after 2000.

Booming suburbs exist in my typology in 2000 and 2005-2009. These neighborhoods have population sizes about twice as large as the average tract population of 4,000 and the largest proportion-about 1/3-of new housing in these years. Their SES profile is the second highest after affluent neighborhoods in these years. This type comprises 1015 percent of neighborhoods at both time periods, and 8 percent of them experienced SES ascent after 2000.

Finally, the sixth neighborhood type in 2005-2009 is a group of Hispanic enclave neighborhoods. This group of urban Hispanic enclaves comprised about 15 percent of all neighborhoods in 2005-2009. Since this type only emerges as a distinct type in 20052009, I do not observe the proportion that ascends over time. However, immigrant enclaves emerge as a type of ascending neighborhood, suggesting an increasing likelihood of ascent for these neighborhoods. I discuss this in the next section. 
Overall, looking at neighborhood types and the proportion that ascend at each point in time illustrates that neighborhoods' origins matter in determining if they ascend or not. In general, the highest proportion of "no population" tracts ascended, because their SES profiles could only go up. New white suburbs had the second highest proportion of ascending tracts. This result emphasizes the role of sprawl and suburbanization in creating new opportunities for upwardly mobile residents and in changing the distribution of neighborhood SES in metropolitan areas. Table 4 also shows that certain neighborhood types were more likely to ascend during some decades than others, reflecting individuals' changing preferences for where they move, the changing likelihoods that existing residents of certain types of neighborhoods experience an increase in their own SES, and/or the changing involvement of government or private interests in generating ascent. In particular, minority urban neighborhoods are increasingly likely to experience SES ascent over time, suggesting that higher-SES residents have become more likely to find these neighborhoods attractive, though also suggesting the risk of displacement for poor residents. I discuss this further in the next section. At the other end of the SES spectrum, upper-middle-class white suburbs are also more likely to experience ascent over time, suggesting a transition of these neighborhoods to an extremely affluent status reflecting the increase in economic segregation over time (Reardon and Bischoff 2011). This section demonstrates the diverse range of neighborhood types experiencing SES ascent. In the next section, I examine population and housing changes accompanying SES ascent to identify the ascent processes that may be occurring among each neighborhood type.

\section{ASCENDING NEIGHBORHOOD TYPES AND PROCESSES}

In the previous section, I described the types of neighborhoods that existed at the start of each decade since 1970 and the proportion of these neighborhoods that experienced SES ascent, defined as a 10-point or greater increase in the percentile distribution of neighborhood SES factor scores within the neighborhood's MSA, over each decade. In this section, I create a separate neighborhood typology only for neighborhoods that ascended in each decade to (1) see if types of neighborhoods emerge among ascending neighborhoods but not all neighborhoods; and (2) examine the population and housing changes among neighborhoods that ascended to explore the processes underlying ascent.

I conduct PCA and cluster analyses only among the ascending neighborhoods in each decade. I include the 14 population and housing variables described in Table 2 for both the beginning and end years of each decade but do not include neighborhood SES variables because I only analyze ascending neighborhoods. For example, to examine the types of neighborhoods that ascended from 1970 to 1980 , I perform PCA on the 14 population and housing variables in both 1970 and 1980 only for tracts that ascended during this time. Five factors had eigenvalues above 1 . Therefore, I perform cluster analysis as described previously, specifying five neighborhood clusters. From 1980 to 1990 , 1990 to 2000, and 2000 to 2005-2009, seven types of ascending neighborhoods existed. I label each type according to the characteristics that distinguished them from others in terms of either their stable or changing traits. Table 5 presents the proportion of ascending neighborhoods accounted for by each neighborhood type from 1970 to 2005-2009. 
TABLE 5. Ascending Neighborhood Types as a Proportion of All Ascending Neighborhoods

\begin{tabular}{|c|c|c|c|c|}
\hline & $1970-1980$ & $1980-1990$ & 1990-2000 & 2000-2009 \\
\hline Minority urban neighborhoods & 6.93 & 6.00 & 7.99 & 14.08 \\
\hline Hispanic enclaves & 5.13 & 8.20 & 7.81 & 12.06 \\
\hline New white suburbs & 44.06 & 20.95 & 11.78 & \\
\hline Affluent neighborhoods & 18.04 & 14.25 & & \\
\hline No population to white suburbs & 25.83 & 9.74 & & \\
\hline Booming suburbs & & 16.57 & 18.28 & 11.98 \\
\hline Upper-middle-class white suburbs & & 24.28 & 33.72 & 39.20 \\
\hline Diverse metropolitan neighborhoods & & & 17.23 & 7.52 \\
\hline Hispanic/Asian immigrant neighborhoods & & & 3.19 & 4.52 \\
\hline Urban white influx & & & & 10.65 \\
\hline Total & $100 \%$ & $100 \%$ & $100 \%$ & $100 \%$ \\
\hline Total $\mathrm{N}$ of ascending neighborhoods & 10,587 & 8,399 & 6,969 & 7,039 \\
\hline
\end{tabular}

As Table 5 shows, many of the ascending neighborhood types are the same as types among all metropolitan neighborhoods, and unless noted in this section, Tables 2 and 3 describe these neighborhood types as well. Minority urban neighborhoods and Hispanic enclaves exist among ascending neighborhoods in all decades and represent a small but increasing proportion of ascending neighborhoods over time. Four types of suburban neighborhoods exist among ascending neighborhoods over time, reflecting a "life course" of suburbs: creation, growth, stability, and transition. (The no population to white suburbs category captures the creation of new white suburbs like those in the full typology while new white suburbs are newly established but do exist at the start of each decade.) In each decade, one of the suburban categories accounts for the most ascending tracts.

Affluent neighborhoods are a distinct type of ascending neighborhood only through 1990 and account for 14-18 percent of ascending neighborhoods in either decade. Metropolitan diverse neighborhoods represent a diverse set of neighborhoods, like urban diverse neighborhoods, but I call them metropolitan because from 1990 to 2000, about 65 percent were in central cities, while only 45 percent were in central cities after 2000. A decreasing proportion of ascending neighborhoods fall into this type over time.

Two of the ascending neighborhood types-Hispanic/Asian immigrant neighborhoods and urban white influx-were not classified as distinct types in analyses among all metropolitan tracts. I describe these neighborhood types below before describing population and housing changes that occur among ascending neighborhoods.

\section{NEIGHBORHOOD TYPES UNIQUE AMONG ASCENDING NEIGHBORHOODS}

Two types of neighborhoods among ascending neighborhoods after 1990 are not in the typology of all metropolitan tracts. Descriptive statistics for these two types of neighborhoods are presented in Table 6.

The first unique type among ascending neighborhoods is Hispanic/Asian immigrant neighborhoods. Assimilation theory suggests that upwardly mobile immigrants leave ethnic enclaves when they are able to, but Logan, Zhang, and Alba (2002) describe how upwardly mobile immigrants establish ethnic communities in desirable areas due to their 
TABLE 6. Descriptive Statistics for Ascending Neighborhood Types Not Found among All Metropolitan Tracts

\begin{tabular}{|c|c|c|c|c|c|c|}
\hline & \multicolumn{4}{|c|}{ Hispanic/Asian Immigrant } & \multicolumn{2}{|c|}{ Urban White Influx } \\
\hline & 1990 & 2000 & 2000 & 2005-2009 & 2000 & 2005-2009 \\
\hline$\%$ Non-Hispanic white & $44.70 \%$ & $36.84 \%$ & $36.97 \%$ & $33.40 \%$ & $59.35 \%$ & $64.83 \%$ \\
\hline$\%$ Non-Hispanic black & $8.10 \%$ & $7.59 \%$ & $6.95 \%$ & $6.03 \%$ & $19.81 \%$ & $15.17 \%$ \\
\hline$\%$ Non-Hispanic Asian & $25.10 \%$ & $36.76 \%$ & $35.95 \%$ & $36.49 \%$ & $4.84 \%$ & $5.05 \%$ \\
\hline$\%$ Hispanic & $18.43 \%$ & $18.07 \%$ & $19.27 \%$ & $18.77 \%$ & $12.85 \%$ & $11.38 \%$ \\
\hline$\%$ Foreign-born & $32.59 \%$ & $41.93 \%$ & $40.39 \%$ & $40.84 \%$ & $12.54 \%$ & $12.70 \%$ \\
\hline Tract population & 3340.51 & 4001.02 & 4092.21 & 4372.93 & 2541.15 & 2600.58 \\
\hline Number of HHs & 1271.25 & 1507.19 & 1437.71 & 979.66 & 1029.93 & 874.98 \\
\hline$\%$ New housing & $13.12 \%$ & $15.83 \%$ & $8.49 \%$ & $9.06 \%$ & $6.77 \%$ & $11.07 \%$ \\
\hline$\%$ Children under 18 & $19.86 \%$ & $19.48 \%$ & $21.80 \%$ & $20.46 \%$ & $13.13 \%$ & $10.97 \%$ \\
\hline$\%$ Children under 5 & $7.21 \%$ & $5.81 \%$ & $6.07 \%$ & $6.42 \%$ & $3.84 \%$ & $3.67 \%$ \\
\hline$\%$ People over 65 & $11.55 \%$ & $10.92 \%$ & $11.98 \%$ & $12.17 \%$ & $9.11 \%$ & $7.56 \%$ \\
\hline$\%$ Female headed HHs & $22.27 \%$ & $21.07 \%$ & $22.16 \%$ & $7.97 \%$ & $33.75 \%$ & $10.92 \%$ \\
\hline Central city & \multicolumn{2}{|c|}{$69.37 \%$} & \multicolumn{2}{|c|}{$70.13 \%$} & \multicolumn{2}{|c|}{$92.00 \%$} \\
\hline Poverty rate & $16.02 \%$ & $15.40 \%$ & $15.39 \%$ & $12.71 \%$ & $23.98 \%$ & $22.10 \%$ \\
\hline Avg HH Income & $\$ 58,851$ & $\$ 79,331$ & $\$ 76,199$ & $\$ 85,522$ & $\$ 51,208$ & $\$ 64,354$ \\
\hline Avg house value & $\$ 252,534$ & $\$ 381,825$ & $\$ 303,264$ & $\$ 514,481$ & $\$ 160,502$ & $\$ 302,599$ \\
\hline Avg rent & $\$ 968$ & $\$ 1,161$ & $\$ 1,160$ & $\$ 1,419$ & $\$ 759$ & $\$ 953$ \\
\hline$\%$ With BA & $23.17 \%$ & $36.63 \%$ & $27.74 \%$ & $39.26 \%$ & $28.17 \%$ & $43.94 \%$ \\
\hline$\%$ With high-status job & $28.76 \%$ & $41.96 \%$ & $33.46 \%$ & $42.54 \%$ & $33.25 \%$ & $47.45 \%$ \\
\hline $\mathrm{N}$ & 222 & & 318 & & 750 & \\
\hline
\end{tabular}

Notes: The racial composition variables do not sum to $100 \%$ because they are the averages of racial composition across all neighborhoods in the cluster, rather than the racial composition of all people in the cluster. Additionally, I do not include American Indian or other racial/ethnic groups.

preferences to self-segregate and preserve ethnic identity. From 1990 to 2000, the average proportion white among Hispanic/Asian immigrant neighborhoods declined from 45 to 37 percent while the average proportion Asian increased from 25 to 37 percent. The average proportion Hispanic in these neighborhoods remained around 18 percent over time. These means are for the cluster and do not suggest that individual neighborhoods are necessarily comprised of both Asian and Hispanic residents. These neighborhoods are not low-SES to begin with and end up with upper-middle-class SES profiles, suggesting that a process of racial/ethnic transition and the creation of ethnic communities is driving ascent, rather than gentrification of previously disinvested neighborhoods. More than 2/3 of neighborhoods are in cities, and a quarter of all tracts in this cluster are in New York City, with another 5 percent each in Chicago, Los Angeles, and San Francisco, suggesting that these are upwardly mobile immigrant communities in cities with large immigrant populations. This group represents less than 5 percent of ascending neighborhoods during the 1990s and 2000s.

The second type of neighborhood distinct only among ascending neighborhoods is urban white influx, which account for about 11 percent of ascending neighborhoods during the 2000s. These neighborhoods were about 60 percent white in 2000 but became 65 percent white, mostly losing black residents during this time. The number of households declines by over 60 percent, perhaps suggesting conversion of multi-unit homes into single family homes or the demolition of subsidized housing, and the proportion of families headed by a single female drops dramatically. Among all types of ascending neighborhoods in this decade, this group experiences the largest percentagepoint increase $(\sim 10-15$ points, respectively) in the proportion of residents with a BA or a 
high-status job. These neighborhoods, 92 percent of which are in cities, could be ascending through gentrification, with white urban pioneers taking advantage of low-cost real estate in city neighborhoods, potentially displacing lower-SES minority residents.

\section{SES ASCENT, POPULATION AND HOUSING CHANGES, AND PROCESS}

Neighborhood ascent occurs through population changes, incumbent residents becoming higher-SES, and/or improvements to the built environment-neighborhoods as both groups of residents and as places can ascend. In this section, I describe population and housing stock changes to identify potential processes of ascent. I cannot distinguish between existing residents experiencing SES increases and higher-SES in-movers with similar race/ethnicity, nativity, and family structure who displace existing residents. However, I can identify changes in tract-level population composition and housing that co-occur with ascent, allowing me to speculate about process, as summarized in Table 3. Gentrification may occur in some of these neighborhoods, but many do not become wealthy neighborhoods, experience changes to the housing stock, or begin as disinvested neighborhoods, key components of gentrification.

\section{Population Changes}

Most ascending neighborhood types experience increases in population size, suggesting some new residents, who may or may not be higher-SES, are moving in. While new residents may be moving in, all ascending neighborhood types have stable tract-level demographic profiles while they experience SES ascent, except for: minority urban neighborhoods after 2000, Hispanic enclaves in the 1970s, no population to white suburbs, and booming suburbs.

In each decade, minority urban neighborhoods experienced ascent. Very little tract-level demographic change occurred as these neighborhoods ascended except after 2000. From 2000 to 2005-2009, these neighborhoods experienced dramatic declines (30 percentage points) in the number of households and female-headed households, accompanied by a slight increase in proportion white (3 points), a decline in proportion black (6 points), and a near doubling of house values. The poverty rate decreases from around 35 to 30 percent and the mean household income increases from around $\$ 30,000$ to $\$ 35,000$ $\$ 40,000$. These neighborhoods are still poor but beginning to transition out of concentrated poverty status. Like urban white influx neighborhoods, these neighborhoods may be ascending through gentrification, the loss of public housing, or other government intervention (Freeman 2006; Hyra 2008). White residents have become more likely to move into lower-class black neighborhoods over time, perhaps suggesting that racial preferences have become secondary to other neighborhood amenities or investment opportunities.

Among all metropolitan neighborhoods, Hispanic enclaves were absorbed into other types of neighborhoods, such as diverse urban, prior to 2005-2009, but they emerge as a distinct type of ascending neighborhoods in all decades. From 1970 to 1980, there is a sharp decline in white residents (from 90 percent to 68 percent) and an increase in Hispanic residents (from 38 percent to 43 percent) as these neighborhoods ascend, perhaps suggesting that white residents' preferences about the proportion of Hispanics in their neighborhood led to white outmigration (Schelling 1971; Bruch and Mare 2006). ${ }^{12}$ After 
1980, there are more modest declines in white residents and increases in Hispanic and foreign-born residents. Like Hispanic/Asian immigrant neighborhoods, these neighborhoods could be ascending through racial transitions and the creation of high-SES immigrant communities (Logan, Zhang, and Alba 2002).

Looking at "before" and "after" characteristics of ascending neighborhoods reveals what happened to neighborhoods that initially had no population. During the 1970s and 1980 s, these neighborhoods became over 80 percent white, growing from nearly no population to about 3,000 residents, slightly below the average tract population. Their SES profile reflects a middle-class neighborhood. These neighborhoods may represent suburban sprawl, as they were unsettled parts of metropolitan areas as late as 1970 or 1980. Ascent occurs as new suburbs are created in areas previously not occupied by residents.

Booming suburbs among ascendant tracts have a slightly different character than in the typology among all tracts. This neighborhood type reflects not only growth but racial transition of the suburbs from white to minority residents. Most are categorized as new suburbs in 1980 and booming suburbs in 1990 and 2000. From 1980 to 1990, they are over 90 percent white, but that proportion declines to about 70 percent after 2000, suggesting that these may be suburbs undergoing racial transition as the proportion of suburban black and Hispanic residents increases (Galster 1991). The SES profile remains middle to upper-middle class. Ascent may occur among booming suburbs as middle-class minority residents leave inner-city neighborhoods and create higher-SES communities.

\section{Housing Changes}

By definition, housing values and rents increased in ascending neighborhoods. On average across all decades, housing values increased least in booming suburbs, which became more minority, and upper-middle-class suburbs, where house values were already high. This suggests that improvements to residents' SES, but not necessarily to the built environment, occurred in these two types of suburbs. House values increased the most among Hispanic enclaves, affluent neighborhoods, and urban white influx neighborhoods, suggesting that changes to the character of the neighborhood may be occurring. On average across all decades, $2 / 3$ of the housing stock in ascending new white suburbs was built in the previous decade. Among urban ascending neighborhood types, 10-20 percent of housing was built in the previous decade, with the highest proportion of new housing in ascending Hispanic enclaves and the lowest proportion in minority urban neighborhoods. Hispanic enclaves experience considerable upgrading to the built environment while remaining Hispanic, suggesting gentrification or incumbent upgrading by upwardly mobile immigrants. Minority urban neighborhoods do not experience these changes, suggesting incumbent upgrading without changes to the built environment or in-migration of working-class (not wealthy) residents.

I also examine changes in the proportion of rental housing and occupancy rates among ascendant neighborhood types. Minority urban neighborhoods, Hispanic enclaves, and Hispanic/Asian immigrant communities lost the most rental housing over time (but only about a 3-point change on average) and experienced the largest increases in occupancy rates (about a 2-point change). Perhaps traditional gentrification processes of conversion of rental housing to single family homes and movement into disinvested neighborhoods is occurring in some of these neighborhoods. However, marginal gentrification, the influx of working class residents, and government intervention can also lead to these 
changes, so it is difficult to disentangle processes. The suburban ascendant neighborhoods maintained a low and stable proportion of rental housing and high occupancy rates over time, suggesting ascent may occur through exclusionary zoning that prevents rental or low-income housing from being built, ensuring only higher-SES residents can move in (Rothwell and Massey 2008).

Among ascending neighborhoods that did not experience notable tract-level population or housing changes, hypothesizing about process is difficult. Affluent neighborhoods may ascend as high-SES residents seek distance from low-SES neighbors, as described by invasion-succession theories. Additionally, ascent could occur through exclusionary processes such as zoning or because all but high-SES residents are priced out of affluent neighborhoods. Diverse urban neighborhoods could be experiencing incumbent upgrading, marginal gentrification, invasion-succession, or other neighborhood ascent processes, though they do not become wealthy neighborhoods. This article documents the many types of neighborhoods experiencing ascent in addition to gentrification: neighborhoods that may not be initially disinvested, may not undergo population changes or changes to the "character" of the neighborhood, and may not result in wealthy neighborhoods. The results have uncovered considerable heterogeneity in the kinds of neighborhoods that ascend, highlighting the need for new research further exploring the processes behind these changes.

\section{DISCUSSION}

In this article, I document the phenomenon of neighborhood socioeconomic ascent in metropolitan neighborhoods from 1970 to 2009. Past research on ascent focuses on gentrification, but I argue that a broader range of neighborhood ascent requires examination. Using the definition developed in this article, about 20 percent of tracts ascended from 1970 to 1980 , declining to 16 percent from 1980 to 1990 and 14 percent from 1990 to 2000 and again from 2000 to $2005-2009$.

Results reveal that neighborhoods with different demographic and economic profiles have unequal odds of ascending. From 1970 to 1990, tracts that initially have no population and new white suburbs are most likely to ascend. After 2000, the highest proportion of minority urban areas experience SES ascent, with nearly equal proportions of diverse urban neighborhoods and white suburban upper-middle-class neighborhoods also experiencing SES ascent. This suggests that, over time, new types of neighborhoods, particularly some at the low end of the SES spectrum in their metropolitan area, are experiencing increases in the average incomes, house values, rents, educational attainment, and occupational status of residents. Among ascending neighborhoods, in every decade, white suburbs made up the largest proportion of ascending tracts. However, black, Hispanic, Asian, and immigrant neighborhoods made up an increasing proportion of ascending neighborhoods over time.

Tract-level population and housing shifts provide clues about processes of ascent. Ascending Hispanic enclave neighborhoods from 1970 to 1980 experienced a large decline in white residents, perhaps evidence of invasion-succession of upwardly mobile immigrants in previously white areas. The influx of white residents in black and mixed race urban neighborhoods might suggest gentrification and a displacement of lower-SES residents. Ascent can also occur through exclusionary processes in affluent and suburban 
neighborhoods, suburbanization or the conversion of nonresidential neighborhoods, subsidized housing policy and public or private development, incumbent upgrading, and the in-migration of working- and middle-class residents. Many of these processes differ from gentrification because they do not necessarily involve displacement, changes to a neighborhood's built environment or character, an end result of a wealthy neighborhood, or renewal of a previously disinvested place

Distinguishing types and processes of ascent other than gentrification both sharpens the concept of gentrification and provides a fuller and more accurate depiction of neighborhood ascent. Theories of gentrification account for only one specific type of neighborhood ascent in which high-income residents move into previously disinvested neighborhoods, resulting in displacement of low-income groups and a neighborhood with amenities appealing to upper-class residents. Rather than trying to apply the theory of gentrification to many cases of ascent (i.e., suburban gentrification, "student"-ification in college towns, super-gentrification in already wealthy areas [Lees, Wyly, and Slater 2008]), new theories are required. Future research should move toward developing theories of ascent that can account for each of the various processes suggested here, perhaps by relying on evidence from comparative case studies. Further, future research should consider the empirical and conceptual appropriateness of developing a unifying theory of neighborhood ascent to predict what type of processes occur in what type of neighborhoods.

This typology of metropolitan neighborhoods undergoing SES ascent presents mixed results in terms of dynamic place stratification and inequality. On the one hand, white and suburban neighborhoods are among the most likely to ascend, and they represent the largest proportion of neighborhoods that do ascend. The demographic typology of all metropolitan neighborhoods demonstrated that whites are more likely to be present in higher-SES neighborhoods than minority groups, so the ascent of white and suburban neighborhoods perpetuates this inequality-already high SES and white neighborhoods become even higher status. This finding suggests that higher-SES residents have advantages in the place stratification of the city both in terms of stable and changing neighborhood characteristics.

On the other hand, the trajectories of black and minority urban neighborhoods, diverse urban neighborhoods, and Hispanic enclaves seem to be improving over time. Of course, what these analyses cannot tell us is whether this means that poor minority residents will be displaced from these types of neighborhoods by whites or middle-class minorities as the neighborhoods experience SES ascent. That low-SES urban neighborhoods that experience ascent after 2000 gain white residents and lose black residents provides some evidence that displacement may be occurring. In addition, it emphasizes the need for theories of ascent and classic gentrification to identify the conditions under which whites are willing to move into black neighborhoods [Hwang and Sampson (unpublished)]. Conversely, some white suburbs experiencing SES ascent are becoming less white over time, suggesting that some minority families experience upward neighborhood mobility by exiting central city neighborhoods.

Theories of neighborhood inequality emphasize the durability of neighborhoods' economic and racial profiles (Sampson 2012). Analyses here suggest that affluent suburbs continue to grow more affluent, and minority residents accrue comparatively fewer benefits of ascent. Future research should extend these analyses to declining and stable neighborhoods to develop a comprehensive theory of dynamic place stratification and 
the conditions under which minority and lower-SES residents might experience the advantages of neighborhood ascent.

\section{Acknowledgments}

The author gratefully acknowledges the helpful feedback and suggestions of Jackie Hwang, Christopher Jencks, Matt Kaliner, Jeremy Levine, Robert J. Sampson, Daniel Schrage, and members of the Urban Social Processes Workshop at Harvard University. The editor and reviewers also provided excellent suggestions and guidance. This research was conducted while the author was a graduate student at Harvard University and has been supported by a graduate fellowship from the National Science Foundation IGERT program, "Multidisciplinary Program in Inequality \& Social Policy" at Harvard University (Grant No. 0333403).

\section{Notes}

${ }^{1}$ Eighteen MSAs have Primary Metropolitan Statistical Areas (PMSAs) delineating major urban areas inside them. For these MSAs, I used the PMSA as the delineation of the metro area ( $N=331 \mathrm{MSA} / \mathrm{PMSAs}$ and 51,448 tracts). I use the abbreviation MSA to refer to both the MSA or, where relevant, PMSA.

${ }^{2}$ I would prefer to use median income, house value, and rent, since averages can be skewed by very large or very small values, but medians are not available in the NCDB in 1970 or 1980 for income and house values. House values in 1970 and 1980 exclude condominium units, which are included after 1990, so changes in this indicator from 1980 to 1990 may be biased. In addition, neither average nor aggregate house values are available in the 2005-2009 ACS, so I calculated these values from the distribution of house values provided.

${ }^{3}$ I also looked at ascent by dividing neighborhood SES factor scores into quartiles within MSAs and defining change as a shift to a higher quartile. Using a 10-percentage point change instead results in a similar number of tracts ascending each decade but eliminates the artificial quartile boundaries.

${ }^{4}$ As a robustness check, I measured ascent excluding the rent variable, and over 85 percent of tracts were classified as ascending with either measurements in each decade.

${ }^{5}$ Table A2 shows the proportion of neighborhoods that ascend in consecutive decades. Thirty-three of 51,448 neighborhoods experienced ascent in all four decades. If I considered any increase in neighborhood SES percentile score to be ascent (rather than using the 10-point threshold), about 45 percent of tracts have ascended in each decade.

${ }^{6}$ Excluding tracts with no population in 1970, 17.5 percent of tracts ascended from 1970 to 1980 . Excluding tracts with no population in 1980, 15.2 percent of tracts ascended from 1980 to 1990.

${ }^{7}$ See http://www.census.gov/population/estimates/metro-city/cencty.txt for a list of the cities considered central cities in a MSA.

${ }^{8}$ Factor scores are not presented here due to space constraints but are available upon request.

${ }^{9}$ I performed sensitivity analyses specifying different numbers of clusters in each decade. When using one fewer cluster than factors from PCA, the main changes were: the affluent cluster combined with new white suburbs and with diverse urban neighborhoods in 1970; the new white suburb and no population clusters combined in 1980; the diverse and minority urban neighborhood clusters combined in 1990; white middle-class suburbs combined with affluent neighborhoods and with diverse neighborhoods in 2000; and transitioning suburbs combined with affluent neighborhoods and with white middle-class suburbs in 2005-2009. When using one more cluster than factors, the main changes were: the affluent neighborhoods cluster split into urban and suburban neighborhoods in 1970 through 1990; the minority urban neighborhoods split into urban and 


\section{CITY \& COMMUNITY}

suburban neighborhoods in 2000; and neighborhoods from each of the affluent, Hispanic enclave, and white suburban clusters created a new combination category in 2005-2009.

${ }^{10}$ For example, $3 / 4$ of neighborhoods categorized as minority urban neighborhoods in 1970 were categorized as such in 2005-2009. About 50 percent of diverse urban neighborhoods in 1970 emerged as Hispanic enclaves in 2005-2009. About 2/3 of neighborhoods with no population in 1970 were upper-middle-class white suburbs in 2005-2009. Eighty percent of new white suburbs in 1970 were categorized as upper-middle-class or booming suburbs or affluent neighborhoods in 2005-2009. Over two-thirds of affluent neighborhoods in 1970 were categorized as affluent or upper-middle-class white suburbs in 2005-2009.

${ }^{11}$ See Supplemental Material for discussion of analyses omitting neighborhoods with no population.

${ }^{12}$ Since data on race by Hispanic status are not available in the 1970 NCDB, I compare all white, black, and Hispanic residents in 1970 and 1980 ascending neighborhoods to maintain consistent measures over time.

\section{REFERENCES}

Baldassare, Mark. 1992. "Suburban Communities." Annual Review of Sociology 18:475-94.

Brown-Saracino, Japonica (ed). 2010. The Gentrification Debates. New York, NY: Routledge.

Bruch, Elizabeth E., and Robert D. Mare. 2006. "Neighborhood Choice and Neighborhood Change." American Journal of Sociology 112:667-709.

Charles, Camille Zubrinsky. 2003. "The Dynamics of Racial Residential Segregation.” Annual Review of Sociology 29:167-207.

Cole, David B. 1987. "Artists and Urban Redevelopment." The Geographical Review 77(4):391-407.

Davidson, Mark, and Loretta Lees. 2005. "New Build 'Gentrification' and London's Riverside Renaissance." Environment and Planning A 37:1165-90.

Ellen, Ingrid Gould, and Katherine O’Regan. 2008. "Reversal of Fortunes? Lower-income Urban Neighborhoods in the US in the 1990s." Urban Studies 45(4):845-69.

Freeman, Lance. 2006. There Goes the 'Hood: Views of Gentrification from the Ground Up. Philadelphia, PA: Temple University Press.

Galster, George C. 1991. "Black Suburbanization: Has it Changed the Relative Location of Races?” Urban Affairs Quarterly 26:621-28.

Galster, George C., Roberto G. Quercia, Alvaro Cortes, and Ron Malega. 2003. "The Fortunes of Poor Neighborhoods." Urban Affairs Review 39(2):205-27.

Glass, Ruth. 1964. "Introduction: Aspects of Change." Pp. xiii-xxxi in London: Aspects of Change, edited by Centre for Urban Studies. London: MacGibbon \& Kee.

Goetz, Edward G. 2010. "Desegregation in 3D: Displacement, Dispersal and Development in American Public Housing." Housing Studies 25 (2):137-58.

Hackworth, Jason, and Neil Smith. 2001. "The Changing State of Gentrification." Journal of Economic and Social Geography 92(4):464-77.

Hammel, Daniel J., and Elvin K. Wyly. 1996. "A Model for Identifying Gentrified Areas with Census Data." Urban Geography 17:248-68.

Hanlon, Bernadette. 2009. "A Typology of Inner-Ring Suburbs: Class, Race, and Ethnicity in U.S. Suburbia." City E Community 8(3):221-46.

— (ed.). 2011. Once the American Dream: Inner-Ring Suburbs of the Metropolitan United States. Philadelphia, PA: Temple University Press.

Heidkamp, C. Patrick, and Susan Lucas. 2006. "Finding the Gentrification Frontier using Census Data: The Case of Portland, Maine." Urban Geography 27(2):101-25.

Hobbs, Frank, and Nicole Stoops. 2002. Demographic Trends in the 20 ${ }^{\text {th }}$ Century. Census 2000 Special Reports, Series CENSR-4. Washington, DC: U.S. Government Printing Office.

Hwang, Jackelyn, and Robert J. Sampson. Unpublished. "Pathway of Gentrification: Mechanisms of Racialized Renewal in the Contemporary City." Unpublished manuscript.

Hyra, Derek. 2008. The New Urban Renewal: The Economic Transformation of Harlem and Bronzeville. Chicago, IL: University of Chicago Press

Jackson, Kenneth T. 1985. Crabgrass Frontier. New York: Oxford University Press.

Jargowsky, Paul A. 1997. Poverty and Place: Ghettos, Barrios, and the American City. New York, NY: Russell Sage. 
2003. Stunning Progress, Hidden Problems: The Dramatic Decline of Concentrated Poverty in the 1990s. Washington, DC: The Brookings Institution, Center on Urban and Metropolitan Policy.

Jencks, Christopher, and Susan E. Mayer. 1990. "The Social Consequences of Growing Up in a Poor Neighborhood." Pp. 111-86 in Inner-City Poverty in the United States, edited by L.E. Lynn Jr. and M.G.H. McGeary. Washington, DC: National Academy Press.

Lacy, Karyn R. 2007. Blue-Chip Black: Race, Class and Status in the New Black Middle Class. Berkeley, CA: University of California Press.

Lee, Barrett A., and Matthew Marlay. 2007. "The Right Side of the Tracks: Affluent Neighborhoods in the Metropolitan United States.” Social Science Quarterly 88(3):766-89.

Lees, Loretta, Tom Slater, and Elvin Wyly. 2008. Gentrification. London: Routledge.

Ley, David. 1996. The New Middle Class and the Remaking of the Central City. New York, NY: Oxford University Press.

Logan, John R. 1978. "Growth, Politics, and the Stratification of Places." American Journal of Sociology 84(2):40416.

Logan, John R., and Harvey L. Molotch. 1987. Urban Fortunes: The Political Economy of Place. Berkeley: University of California Press.

Logan, John R., Wenquan Zhang, and Richard D. Alba. 2002. "Immigrant Enclaves and Ethnic Communities in New York and Los Angeles.” American Sociological Review 67(2):299-322.

London, Bruce, and J. John Palen. 1984. "Introduction: Some Theoretical and Practical Issues Regarding Inner-City Revitalization.” Pp. 4-26 in Gentrification, Displacement and Neighborhood Revitalization, edited by B. London and J. J. Palen. Albany, NY: SUNY Press.

Massey, Douglas S., and Nancy A. Denton. 1993. American Apartheid: Segregation and the Making of the Underclass. Cambridge, MA: Harvard University Press.

Massey, Douglas S., and Mitchell Eggers. 1990. "The Ecology of Inequality: Minorities and the Concentration of Poverty 1970-1980.” American Journal of Sociology 95:1153-88.

Massey, Douglas S., and Mary J. Fischer. 2003. "The Geography of Inequality in the United States, 1950-2000." Pp. 1-40 in Brookings-Wharton Papers on Urban Affairs: 2003, edited by W. G. Gale and J. R. Pack. Washington, DC: Brookings Institution Press.

McKenzie, R.D. 1925. "The Ecological Approach to the Study of the Human Community." Pp. 63-85 in The City, edited by R. E. Park and E. W. Burgess. Chicago: University of Chicago Press.

McKinnish, Terra, Randall Walsh, and T. Kirk White. 2008. "Who Gentrifies Low-Income Neighborhoods?" Discussion Paper CES 08-02, Center for Economic Studies, U.S. Bureau of the Census.

Molotch, Harvey L. 1976. "The City as a Growth Machine: Toward a Political Economy of Place." American Journal of Sociology 82(2):309-32.

Morenoff, Jeffrey D., and Marta Tienda. 1997. "Underclass Neighborhoods in Temporal and Ecological Perspective." Annals of the American Academy of Political and Social Science 551:59-72.

Park, Robert E., and Ernest W. Burgess. 1925. The City. Chicago: University of Chicago Press.

Pattillo, Mary. 2005. "Black Middle-Class Neighborhoods." Annual Review of Sociology 31:305-29.

2007. Black on the Block: The Politics of Race and Class in the City. Chicago: University of Chicago Press.

Quillian, Lincoln. 1999. "Migration Patterns and the Growth of High-Poverty Neighborhoods, 1970-1990." American Journal of Sociology 105:1-37.

Reardon, Sean F., and Kendra Bischoff. 2011. "Income Inequality and Income Segregation." American Journal of Sociology 116(4):1092-153.

Rose, Damaris. 1984. "Rethinking Gentrification: Beyond the Uneven Development of Marxist Urban Theory." Environment and Planning D: Society and Space 1:57-69.

Rothwell, Jonathan T., and Douglas S. Massey. 2008. "Density Zoning and Class Segregation in U.S. Metropolitan Areas.” SSRN Working Paper 1322128.

Sampson, Robert J. 2012. Great American City: Chicago and the Enduring Neighborhood Effect. Chicago, IL: University of Chicago of Press.

Sampson, Robert J., and Patrick Sharkey. 2008. "Neighborhood Selection and the Social Reproduction of Concentrated Racial Inequality." Demography 45(1):1-29.

Schelling, Thomas. 1971. "Dynamic Models of Segregation.” Journal of Mathematical Sociology 1:143-86.

Schuler, Jill R., Robert B. Kent, and Charles B. Monroe. 1992. "Neighborhood Gentrification: A Discriminant Analysis of a Historic District in Cleveland, Ohio." Urban Geography 13:49-67.

Schwirian, Kent P. 1983. "Models of Neighborhood Change." Annual Review of Sociology 9:83-102.

Smith, Neil. 1979. "Toward a Theory of Gentrification: A Back to the City Movement by Capital, Not People." Journal of the American Planning Association 45(4):538-48. 


\section{CITY \& COMMUNITY}

1986. "Gentrification, the Frontier, and the Restructuring of Urban Space." Pp. 15-34 in Gentrification of the City, edited by N. Smith and P. Williams. Boston, MA: Allen and Unwin.

Sucoff, Clea A., and Dawn M. Upchurch. 1998. "Neighborhood Context and the Risk of Childbearing among Metropolitan-Area Black Adolescents.” American Sociological Review 63(4):571-85.

Squires, Gregory D. (ed.). 2002. Urban Sprawl: Causes, Consequences, and Policy Decisions. Washington, DC: Urban Institute Press.

Taylor, Monique M. 2002. Harlem Between Heaven and Hell. Minneapolis, MN: University of Minnesota Press.

U.S. Census Bureau. 2009. A Compass for Understanding and Using American Community Survey Data: What Researchers Need to Know. Washington, DC: U.S. Government Printing Office.

Van Criekingen, Mathieu, and Jean-Michel Decroly. 2003. "Revisiting the Diversity of Gentrification: Neighborhood Renewal Processes in Brussels and Montreal." Urban Studies 40(12):2451-68.

Wilson, William Julius. 1987. The Truly Disadvantaged: The Inner City, the Underclass, and Public Policy. Chicago, IL: University of Chicago Press.

Wilson, William Julius, and Richard P. Taub. 2006. There Goes the Neighborhood: Racial, Ethnic, and Class Tensions in Four Chicago Neighborhoods and Their Meaning for America. New York, NY: Knopf.

Wyly, Elvin, and James DeFilippis. 2010. "Mapping Public Housing: The Case of New York." City E Community $9(1): 61-86$.

Wyly, Elvin K., and Daniel J. Hammel. 1998. "Modeling the Context and Contingency of Gentrification." Urban Affairs 20(3):303-26.

— 1999. "Islands of Decay in Seas of Renewal: Housing Policy and the Resurgence of Gentrification." Housing Policy Debate 10(4):711-71.

Zukin, Sharon. 1982. Loft Living. Baltimore, ND: Johns Hopkins University Press. 1987. "Gentrification: Culture and Capital in the Urban Core." Annual Review of Sociology 13:129-47.

\section{APPENDIX}

TABLE A1. Rotated Factor Loadings for Neighborhood SES Score

\begin{tabular}{|c|c|c|c|c|c|}
\hline & 1970 & 1980 & 1990 & 2000 & 2005-2009 \\
\hline Avg $\mathrm{HH}$ income & 0.870 & 0.830 & 0.901 & 0.903 & 0.876 \\
\hline Avg rent & -0.195 & 0.816 & 0.830 & 0.815 & 0.697 \\
\hline Avg house values & 0.868 & 0.099 & 0.835 & 0.835 & 0.720 \\
\hline$\%$ with BA & 0.904 & 0.899 & 0.877 & 0.901 & 0.896 \\
\hline$\%$ with high-status job & 0.945 & 0.926 & 0.880 & 0.899 & 0.882 \\
\hline Eigenvalue & 3.260 & 3.029 & 3.740 & 3.797 & 3.351 \\
\hline Proportion of variance explained & 0.652 & 0.606 & 0.748 & 0.759 & 0.670 \\
\hline
\end{tabular}

TABLE A2. Number and Proportion of Ascending Neighborhoods that Experience Ascent in Subsequent Decades

\begin{tabular}{|c|c|c|c|c|c|c|}
\hline & & \multicolumn{3}{|c|}{ Ascended From } & \multirow[b]{2}{*}{ No Further Ascent } & \multirow[b]{2}{*}{ Total } \\
\hline & & $80-90$ & $90-00$ & 00-09 & & \\
\hline \multirow[t]{6}{*}{ Ascended from } & $70-80$ & 1,590 & 1,784 & 1,496 & 5,717 & 10,587 \\
\hline & & $15.02 \%$ & $16.85 \%$ & $14.13 \%$ & $54.00 \%$ & $100 \%$ \\
\hline & $80-90$ & & 1,533 & 1,480 & 5,386 & 8,399 \\
\hline & & & $18.25 \%$ & $17.62 \%$ & $64.13 \%$ & $100 \%$ \\
\hline & $90-00$ & & & 1,254 & 5,715 & 6,969 \\
\hline & & & & $17.99 \%$ & $82.00 \%$ & $100 \%$ \\
\hline
\end{tabular}




\section{Barrios en Mejora: Una Tipología de Barrios en Proceso de Ascenso Socioeconómico.} (Ann Owens)

\section{Resumen}

Los barrios son una fuente importante de desigualdades y los cambios en estos generan cambios en las oportunidades de sus residentes. Investigaciones anteriores sobre barrios en mejora tienden a centrarse en un proceso: gentrificación. Propongo que una tipología con un espectro más amplio de tipos de barrios amerita atención. Este artículo registra los distintos tipos de barrios en mejora desde 1970 hasta el presente. Usando análisis de componentes de principio (Principle Components Analysis) y análisis de conglomerados (Cluster Analysis), reporto la prevalencia de ascenso de SES, en base al aumento al ingreso promedio en el barrio, alquileres, el valor de las casas, y el logro educacional y ocupacional, con entre 5 y 7 tipos de barrio en cada década. También examino cambios en la población y vivienda que ocurren a la par que la mejora del barrio para identificar procesos de mejora distintos a la gentrificación. En suma, los resultados sugieren implicancias distintas para la desigualdad en barrios. Mientras barrios blancos suburbanos forman la mayoría de barrios que mejoran en cada década, los barrios de minorías y de inmigrantes se tornan cada vez más propensos a mejorar en el futuro, aunque podrían ocurrir expulsiones de estos grupos.

\section{Supporting Information}

The following supporting information is available for this article:

\section{Supplemental Material S1:}

Supporting Information may be found in the online version of this article.

Please note: Wiley-Blackwell is not responsible for the content or functionality of any supporting information supplied by the authors. Any queries (other than missing material) should be directed to the corresponding author for the article. 